British Journal of Nutrition (2014), 112, 1137-1146

doi: $10.1017 /$ S0007114514001640

(c) The Authors 2014. The online version of this article is published within an Open Access environment subject to the conditions of the Creative Commons Attribution-NonCommercial-ShareAlike licence $<$ http://creativecommons.org/licenses/by-nc-sa/3.0/ $>$. The written permission of Cambridge University Press must be obtained for commercial re-use.

\title{
Effect of almond consumption on the serum fatty acid profile: a dose-response study
}

\author{
Stephanie Nishi ${ }^{1,2}$, Cyril W. C. Kendall ${ }^{1,2,3 *}$, Ana-Maria Gascoyne ${ }^{1,2}$, Richard P. Bazinet ${ }^{1}$, \\ Balachandran Bashyam ${ }^{1,2}$, Karen G. Lapsley ${ }^{4}$, Livia S. A. Augustin ${ }^{2}$, John L. Sievenpiper ${ }^{1,2,5,6,7}$ and \\ David J. A. Jenkins ${ }^{1,2,6,7,8}$ \\ ${ }^{1}$ Department of Nutritional Sciences, Faculty of Medicine, University of Toronto, Toronto, ON, Canada M5S $3 E 2$ \\ ${ }^{2}$ Clinical Nutrition and Risk Factor Modification Center, St Michael's Hospital, Toronto, ON, Canada \\ ${ }^{3}$ Division of Nutrition and Dietetics, College of Pharmacy and Nutrition, University of Saskatchewan, Saskatoon, SK, Canada \\ ${ }^{4}$ The Almond Board of California, Modesto, CA, USA \\ ${ }^{5}$ Department of Pathology and Molecular Medicine, Faculty of Health Sciences, McMaster University, Hamilton, ON, Canada \\ ${ }^{6}$ Division of Endocrinology and Metabolism, St Michael's Hospital, Toronto, ON, Canada \\ ${ }^{7}$ Li Ka Shing Knowledge Institute, St Michael's Hospital, Toronto, ON, Canada \\ ${ }^{8}$ Department of Medicine, Faculty of Medicine, University of Toronto, Toronto, ON, Canada
}

(Submitted 15 September 2013 - Final revision received 16 January 2014 - Accepted 11 February 2014 - First published online 20 August 2014)

\section{Abstract}

Consumption of almonds has been shown to be associated with a decreased risk of CHD, which may be related to their fatty acid (FA) composition. However, the effect of almond consumption on the serum FA composition is not known. Therefore, in the present study, we investigated whether almond consumption would alter the serum FA profile and risk of CHD, as calculated using Framingham's 10-year risk score, in a dose-dependent manner in hyperlipidaemic individuals when compared with a higher-carbohydrate control group using dietary interventions incorporating almonds. A total of twenty-seven hyperlipidaemic individuals consumed three isoenergetic (mean $1770 \mathrm{~kJ} / \mathrm{d}$ ) supplements during three 1-month dietary phases: (1) full-dose almonds (50-100 g/d); (2) half-dose almonds with halfdose muffins; (3) full-dose muffins. Fasting blood samples were obtained at weeks 0 and 4 for the determination of FA concentrations. Almond intake $(\mathrm{g} / \mathrm{d})$ was found to be inversely associated with the estimated Framingham 10-year CHD risk score $(P=0 \cdot 026)$. In both the half-dose and full-dose almond groups, the proportions of oleic acid (OA) and MUFA in the TAG fraction (half-almond: OA $P=0.003$; MUFA $P=0.004$; full-almond: OA $P<0.001$; MUFA $P<0.001$ ) and in the NEFA fraction (half-almond: OA $P=0.01$; MUFA $P=0.04$; full-almond: OA $P=0 \cdot 12$; MUFA $P=0 \cdot 06$ ) increased. The estimated Framingham 10 -year CHD risk score was inversely associated with the percentage change of OA $(P=0.011)$ and MUFA $(P=0.016)$ content in the TAG fraction. The proportions of MUFA in the TAG and NEFA fractions were positively associated with changes in HDL-cholesterol concentrations. Similarly, the estimated Framingham 10-year CHD risk score was inversely associated with the percentage change of OA $(P=0.069)$ and MUFA content in the NEFA fraction $(P=0.009)$. In conclusion, the results of the present study indicate that almond consumption increases OA and MUFA content in serum TAG and NEFA fractions, which are inversely associated with CHD lipid risk factors and overall estimated 10-year CHD risk.

Key words: Coronary/heart disease: Fatty acids: Nutrition: Almonds

Epidemiological $^{(1-4)}$ and clinical studies ${ }^{(5,6)}$ have shown that nut consumption decreases the risk of developing CHD and improves blood lipid risk factors. Almond consumption has been shown to reduce LDL-cholesterol (LDL-C) concentrations and increase HDL-cholesterol (HDL-C) concentrations in hyperlipidaemic individuals ${ }^{(7,8)}$. Although almonds contain a variety of constituents that may exert cardioprotective effects through various mechanisms ${ }^{(9)}$, their ability to improve blood lipid profiles and reduce CHD risk may primarily be related to their healthy fatty acid (FA) profile, which is low in saturated fats (SFA) and high in monounsaturated fats $(\text { MUFA })^{(10,11)}$, particularly oleic acid $(\mathrm{OA})^{(12,13)}$. Epidemiological studies suggest that diets with a high proportion of MUFA in the form of OA, such as the Mediterranean diet, reduce

Abbreviations: FA, fatty acids; HDL-C, HDL-cholesterol; LDL-C, LDL-cholesterol; OA, oleic acid; PREDIMED, Prevención con Dieta Mediterránea. 
CHD risk ${ }^{(14,15)}$. However, the effect of almond consumption on the serum FA profile and its association with $\mathrm{CHD}$ risk have not been investigated.

Therefore, in the present study, we investigated whether almond consumption would alter the serum FA profile and risk of CHD, as calculated using Framingham's 10-year risk score, in a dose-dependent manner in hyperlipidaemic individuals compared with a higher-carbohydrate control group using dietary interventions incorporating almonds ${ }^{(7)}$. This is a secondary analysis of a trial that primarily aimed to assess the effect of almond consumption on blood lipid risk factors for $\mathrm{CHD}^{(7)}$.

\section{Methods}

The study methods have been described in detail previously ${ }^{(7)}$.

\section{Study protocol}

A total of twenty-seven subjects completed three 1-month dietary phases in a randomised cross-over manner, with each phase being separated by a washout period of minimum 2 weeks. The three dietary phases comprised a muffin phase (control) and two almond phases: full-dose almond phase and half-dose almond plus half-dose muffin phase. During all the dietary phases, the subjects followed their own self-selected, low-fat therapeutic diets into which they incorporated the supplements. The subjects were counselled on strategies to facilitate weight maintenance.

After an overnight fast $(12-14 \mathrm{~h})$, body weight measurements, blood samples and blood pressure measurements were obtained at the start of the study and at weeks 2 and 4 of each 4-week dietary phase. Before baseline and at week 4 of each dietary phase, $7 \mathrm{~d}$ diet records were obtained from the subjects. The subjects were instructed to weigh all the food consumed with the self-rating electronic food scales provided during the weeks when dietary intake was recorded.

The present study was conducted according to the guidelines laid down in the Declaration of Helsinki, and all procedures involving human subjects were approved by the Ethics Committee of the University of Toronto and St Michael's Hospital. Written informed consent was obtained from all subjects. The present trial was registered at ClinicalTrials.gov (no. NCT00507520).

\section{Study subjects}

Healthy hyperlipidaemic men and postmenopausal women were recruited through newspaper advertisement and from among patients visiting the Risk Factor Modification Centre of St Michael's Hospital, a University of Toronto teaching hospital. As has been reported previously ${ }^{(7)}$, sixteen of the forty-three subjects who were initially recruited withdrew during or after completing one or two dietary phases: three discontinued for reasons directly related to the study (food allergies, $n$ 2; abdominal discomfort, $n$ 1) and thirteen withdrew for unrelated reasons. The characteristics of these sixteen subjects were similar to those of the subjects who completed the study. The remaining twenty-seven subjects completed all the three dietary phases: fifteen men and twelve postmenopausal women (mean age 64 (SD 9) years (range: $48-86$ years; four subjects aged $\geq 75$ years); mean BMI 25.7 (SD 3.0$) \mathrm{kg} / \mathrm{m}^{2}$ (range: $20.5-31.5 \mathrm{~kg} / \mathrm{m}^{2}$ ) and mean baseline LDL-C concentrations 4.32 (SD 0.63 ) $\mathrm{mmol} / \mathrm{l}$ (range $2 \cdot 77-5 \cdot 32 \mathrm{mmol} / \mathrm{l}$ )). All subjects had elevated LDL-C concentrations during initial assessment at recruitment $(>4.1 \mathrm{mmol} / \mathrm{l})$, despite lower values being detected in some subjects at baseline, and TAG concentrations $<4.0 \mathrm{mmol} / \mathrm{l}$. None of the subjects used tobacco and had clinical or biochemical evidence of diabetes, liver disease or renal disease. Among the twenty-seven subjects, three men and five women were taking the following medications: a hypolipidaemic agent (statin) ( $n$ 2); $\beta$-blocking agents ( $n$ 3); angiotensin-converting enzyme inhibitors ( $n 3)$; angiotensin II receptor blockers ( $n$ 1); thiazide diuretics ( $n$ 2); levothyroxine ( $n$ 2); hormone replacement therapy ( $n$ 2). Medication use was stable for at least 2 weeks before the study. Medication dosages were kept constant throughout the study. The subjects were asked to maintain their habitual levels of physical activity throughout the study.

\section{Diets}

Before the start of the study, all subjects had been instructed to follow a therapeutic National Cholesterol Education Program Step 2 diet ( $<7 \%$ energy from saturated fats and $<200 \mathrm{mg} / \mathrm{d}$ dietary cholesterol). All subjects took all the three supplements: whole raw unblanched almonds (73 (SD 3) g/d); muffins (147 (SD 6) g/d); and half portions of almonds (37 (SD 2) g/d) plus muffins (75 (SD 3) g/d), as described previously $^{(6)}$. The amount of supplements ingested was based on the estimated daily energy requirement of the subjects ${ }^{(16)}$. For subjects requiring $<6694 \mathrm{~kJ} / \mathrm{d}(<1600 \mathrm{kcal} / \mathrm{d})$, the full portions of almonds and muffins were $50 \mathrm{~g}$ (one package) and $100 \mathrm{~g}$ (two muffins), respectively $(1201 \mathrm{~kJ} / \mathrm{d}(287 \mathrm{kcal} / \mathrm{d})$ supplement). The respective values for those requiring $6694-10042 \mathrm{~kJ} / \mathrm{d}(1600-2400 \mathrm{kcal} / \mathrm{d})$ were $75 \mathrm{~g}$ of almonds and $150 \mathrm{~g}$ of muffins (three muffins; $1799 \mathrm{~kJ} / \mathrm{d}(430 \mathrm{kcal} / \mathrm{d}$ ) supplement) and for those requiring $>10042 \mathrm{~kJ} / \mathrm{d}$ (>2400 kcal/d) were $100 \mathrm{~g}$ of almonds and $200 \mathrm{~g}$ of muffins (four muffins; $2402 \mathrm{~kJ} / \mathrm{d}$ ( $574 \mathrm{kcal} / \mathrm{d})$ supplement). During the half-almond plus half-muffin phase, the subjects consumed each supplement at half the full amount for each of the energy requirements described above. The muffins were made from whole-wheat flour with an amount of maize oil sufficient to provide the same amounts of SFA, PUFA and fibre provided by almonds. Skimmed milk powder and eggwhites were used to maintain the level of protein between the supplements, although the protein in the muffins was $46 \%$ animal origin. MUFA (kJ) in almonds balanced the starch in muffins. The macronutrient composition of the muffins as a percentage of energy was as follows: $14.7 \%$ protein; $53.3 \%$ available carbohydrate; $32 \cdot 1 \%$ fat; $4.3 \%$ SFA; $7 \cdot 6 \%$ MUFA; $18.9 \%$ PUFA with $4.3 \mathrm{~g} / 1000 \mathrm{~kJ}$ (18 g/1000 kcal) cholesterol. Non-hydrogenated maize oil was the only fat used in muffin preparation to prevent the addition of trans-FA to the 
supplements. Muffin supplements were provided to the subjects at biweekly intervals and were stored in a freezer until the day before use. The subjects were instructed to reduce their total food intake, especially starchy foods (breads, bagels, non-study muffins and breakfast cereals), to allow supplements to be incorporated in their diet without increasing total energy intake and to keep the background diet constant across all the three dietary phases. To minimise changes in body weight and diet composition, the subjects were given detailed dietary counselling before and at weeks 1 and 2 of each dietary phase. During the study, the subjects were asked to not consume any additional nuts or nut products or alter their intake of dietary fibre or vegetable protein foods. Compliance was assessed from $7 \mathrm{~d}$ diet records, a supplement checklist in which the subjects recorded the supplements consumed, and return of uneaten supplements, which were weighed and recorded.

\section{Analyses}

Serum was analysed according to the Lipid Research Clinics protocol $^{(17,18)}$ for total cholesterol, TAG and HDL-C after dextran sulphate-magnesium chloride precipitation, and LDL-C concentrations were calculated $^{(19)}$ as described previously ${ }^{(7)}$. The present study focused on serum FA concentrations and estimated 10-year CHD risk based on the Framingham equation $^{(16)}$. The following variables were used in the Framingham equation to determine the 10-year CHD risk at baseline and end of each intervention period: age; sex; systolic blood pressure; total cholesterol; HDL-C; total cholesterol:HDL-C ratio; smoking status; diabetes diagnosis. Values obtained for the 10-year CHD risk were then compared with those of the ideal risk, where total cholesterol:HDL-C ratio was set at 4.44 , systolic blood pressure at $120 \mathrm{mmHg}$, and smoking status as non-smoker, to obtain relative risk values.

To assess FA fractions, total lipids were extracted from the serum according to the Folch method ${ }^{(20)}$. TLC plates were activated by heating at $100^{\circ} \mathrm{C}$ for $1 \mathrm{~h}$. Total lipids were then loaded onto the plates and placed in a tank with solvents. FA fractions were separated along with authentic standards in heptane-diethyl ether-glacial acetic acid (60:40:2, v/v). Bands corresponding to total phospholipid, NEFA, TAG and cholesterol esters were visualised under UV light, after staining with 8-anilino-1-naphthalene sulphonic acid $(0 \cdot 1 \%$, w/v). Known amounts of an unesterified heptadecanoic acid standard were added to test-tubes containing hexane and each scraped band. These were converted to FA methyl esters with $14 \%$ boron trifluoride-methanol at $100^{\circ} \mathrm{C}$ for $1 \mathrm{~h}$. FA methyl esters were quantified on a Varian-430 gas chromatograph (Varian, Inc.) equipped with a Varian Factor Four capillary column (VF-23ms, $30 \mathrm{~m} \times 0.25 \mathrm{~mm}$ inner diameter $\times 0.25 \mu \mathrm{m}$ film thickness; Agilent Technologies) and a flame ionisation detector. Samples were injected in splitless mode. The temperature of the injector and detector ports was set at $250^{\circ} \mathrm{C}$. FA methyl esters were eluted using a temperature programme set initially at $50^{\circ} \mathrm{C}$ for $2 \mathrm{~min}$, increased at $20^{\circ} \mathrm{C} / \mathrm{min}$ and held at $170^{\circ} \mathrm{C}$ for $1 \mathrm{~min}$ and then at $3^{\circ} \mathrm{C} / \mathrm{min}$ and held at $212^{\circ} \mathrm{C}$ for $5 \mathrm{~min}$ to complete the run in $28 \mathrm{~min}$.
The carrier gas used was helium, set to a constant flow rate of $0.7 \mathrm{ml} / \mathrm{min}$. Peaks were identified by the retention times of FA methyl ester standards (Nu-Chek-Prep, Inc.). FA concentrations ( $\mathrm{nmol} / \mathrm{ml}$ serum) were calculated by proportional comparison of GC peak areas with that of the heptadecanoic acid internal standard. Plasma SFA, MUFA and PUFA concentrations were calculated by adding the concentrations of all the respective FA with twelve to twenty-four carbon atoms within the treatment groups for each FA fraction, excluding $20: 0$ or $18: 3 n-3$, as these FA did not get separated in the column.

\section{Statistical analyses}

Results are expressed as means with their standard errors. The primary outcomes of the original study were total cholesterol, LDL-C, HDL-C, TAG, apoB and apoA $1^{(7)}$. The present study focused on FA fractions in the serum of subjects who completed the study ( $n$ 27) and estimated CHD risk using the Framingham equation ${ }^{(16)}$.

Treatment effects were tested using Student's $t$ test for within-group analysis and one-way repeated-measures ANOVA for between-group analysis (Microsoft Excel, 2007). Pearson's correlation analyses were conducted to test the associations between FA concentrations and CHD risk (SAS Institute Inc., version 9.3). Statistical significance was set at $P<0.05$ for all analyses.

\section{Results}

\section{Subject characteristics}

The baseline characteristics of the subjects, as well as data obtained at baseline and after the dietary interventions, have been reported previously ${ }^{(7)}$. There were no differences in the effects of dietary treatments on the anthropometric or lipid profiles analysed between those who completed the study and those who did not (see Supplementary table, available online).

Table 1. Fatty acid composition of supplements used in the study (Mean values with their standard errors)

\begin{tabular}{|c|c|c|c|c|}
\hline \multirow[b]{3}{*}{ Fatty acids (\%) } & \multicolumn{4}{|c|}{ Supplements } \\
\hline & \multicolumn{2}{|c|}{ Muffins $(n 3)$} & \multicolumn{2}{|c|}{ Almonds (n 3) } \\
\hline & Mean & SEM & Mean & SEM \\
\hline $14: 0$ & 0.3 & 0.1 & 0.1 & 0.0 \\
\hline $14: 1 n-5$ & 0.0 & 0.0 & 0.0 & 0.0 \\
\hline $16: 0$ & $16 \cdot 3$ & 0.5 & $9.0^{*}$ & 0.0 \\
\hline $16: 1 n-7$ & 0.2 & 0.1 & $0.5^{\star}$ & 0.0 \\
\hline $18: 0$ & 0.2 & 0.1 & 1.7 & 0.0 \\
\hline $18: 1 n-9$ & $21 \cdot 8$ & 0.8 & $64 \cdot 3^{*}$ & 0.0 \\
\hline $18: 1 n-7$ & 0.5 & 0.0 & $1 \cdot 3^{\star}$ & 0.0 \\
\hline $18: 2 n-6$ & $57 \cdot 0$ & 0.1 & $23 \cdot 0^{*}$ & 0.0 \\
\hline $18: 3 n-6$ & 0.0 & 0.0 & 0.0 & 0.0 \\
\hline $20: 0 / 18: 3 n-3$ & 1.7 & 0.0 & 0.0 & 0.0 \\
\hline $20: 1 n-9$ & 0.2 & 0.0 & $0.0^{*}$ & 0.0 \\
\hline Total $(\mathrm{mg} / \mathrm{g})$ & $9 \cdot 4$ & $1 \cdot 1$ & $24 \cdot 8^{*}$ & $1 \cdot 1$ \\
\hline
\end{tabular}

${ }^{*}$ Mean values were significantly different from that of the muffin-supplemented group $(P<0.05)$. 
Table 2. Effect of dietary treatments on the proportion of fatty acids in the serum phospholipid fraction (Mean values with their standard errors)

\begin{tabular}{|c|c|c|c|c|c|c|c|c|c|c|c|c|}
\hline \multirow[b]{4}{*}{ Fatty acids (\%) } & \multicolumn{12}{|c|}{ Dietary treatments } \\
\hline & \multicolumn{4}{|c|}{ Control (n 27) } & \multicolumn{4}{|c|}{ Half-dose almonds ( $n$ 27) } & \multicolumn{4}{|c|}{ Full-dose almonds ( $n$ 27) } \\
\hline & \multicolumn{2}{|c|}{ Week 0} & \multicolumn{2}{|c|}{ Week 4} & \multicolumn{2}{|c|}{ Week 0} & \multicolumn{2}{|c|}{ Week 4} & \multicolumn{2}{|c|}{ Week 0} & \multicolumn{2}{|c|}{ Week 4} \\
\hline & Mean & SEM & Mean & SEM & Mean & SEM & Mean & SEM & Mean & SEM & Mean & SEM \\
\hline $14: 0$ & 0.55 & 0.03 & 0.56 & 0.03 & 0.64 & 0.04 & $0.56^{*}$ & 0.05 & 0.56 & 0.03 & 0.57 & 0.03 \\
\hline $14: 1 n-5$ & 0.03 & 0.01 & 0.03 & 0.01 & 0.19 & 0.14 & 0.03 & 0.01 & 0.03 & 0.01 & 0.07 & 0.03 \\
\hline $16: 0$ & 35.57 & 0.50 & $35 \cdot 17$ & 0.51 & 35.84 & 0.52 & 34.93 & 0.66 & 35.04 & 0.41 & 34.51 & 0.45 \\
\hline $16: 1 n-7$ & 0.80 & 0.06 & 0.75 & 0.04 & 0.97 & 0.15 & 0.72 & 0.05 & 0.76 & 0.04 & 0.76 & 0.05 \\
\hline $18: 0$ & 14.62 & 0.23 & 14.71 & 0.22 & 14.51 & 0.25 & $14 \cdot 19$ & 0.24 & 14.75 & 0.27 & $14 \cdot 39$ & 0.23 \\
\hline $18: 1 n-9$ & $10 \cdot 28$ & 0.24 & 10.52 & 0.22 & 10.27 & 0.24 & $10.64^{*}$ & 0.22 & 9.96 & 0.24 & $10 \cdot 80^{*}$ & 0.20 \\
\hline $18: 1 n-7$ & 1.59 & 0.05 & 1.69 & 0.05 & 1.60 & 0.05 & 1.64 & 0.06 & 1.62 & 0.05 & 1.94 & 0.36 \\
\hline $18: 2 n-6$ & $19 \cdot 31$ & 0.45 & 19.80 & 0.45 & $19 \cdot 42$ & 0.46 & $20 \cdot 21^{*}$ & 0.42 & 19.67 & 0.54 & $20 \cdot 27$ & 0.83 \\
\hline $18: 3 n-6$ & 0.12 & 0.02 & 0.20 & 0.07 & 0.15 & 0.06 & 0.14 & 0.06 & 0.16 & 0.06 & 0.85 & 0.71 \\
\hline $20: 0 / 18: 3 n-3$ & 0.44 & 0.04 & 0.47 & 0.04 & 0.45 & 0.04 & 0.44 & 0.04 & 0.42 & 0.04 & 0.39 & 0.04 \\
\hline $20: 1 n-9$ & $0 \cdot 14$ & 0.01 & 0.16 & 0.01 & 0.13 & 0.01 & $0.17^{*}$ & 0.01 & 0.13 & 0.01 & $0 \cdot 17$ & 0.02 \\
\hline $20: 3 n-3 \dagger$ & 0.29 & 0.02 & $0.32^{*}$ & 0.01 & 0.30 & 0.01 & 0.27 & 0.02 & 0.30 & 0.01 & 0.29 & 0.01 \\
\hline AA $(20: 4 n-6)$ & 9.45 & 0.28 & 9.02 & 9.02 & 9.32 & 0.39 & $9 \cdot 36$ & 0.37 & 9.49 & 0.36 & 8.94 & 0.49 \\
\hline $22: 0$ & 0.04 & 0.03 & 0.00 & 0.00 & 0.01 & 0.01 & 0.06 & 0.04 & 0.03 & 0.03 & 0.04 & 0.03 \\
\hline $22: 1 n-9$ & 0.11 & 0.06 & 0.08 & 0.02 & 0.06 & 0.01 & 0.05 & 0.01 & 0.09 & 0.04 & 0.35 & 0.32 \\
\hline EPA $(20: 5 n-3) \dagger$ & 1.27 & 0.15 & 1.22 & 0.09 & $1 \cdot 10$ & 0.10 & 1.31 & 0.14 & 1.40 & 0.17 & $0.96^{*}$ & 0.11 \\
\hline $22: 4 n-6$ & 0.23 & 0.02 & 0.23 & 0.02 & 0.22 & 0.02 & $0.19^{*}$ & 0.01 & 0.35 & 0.14 & 0.21 & 0.03 \\
\hline $24: 1 n-9$ & 0.27 & 0.09 & 0.23 & 0.09 & 0.17 & 0.07 & 0.28 & $0 \cdot 10$ & 0.26 & 0.10 & 0.25 & 0.09 \\
\hline $22: 5 n-6$ & 0.76 & 0.10 & 0.85 & 0.11 & 0.83 & 0.11 & 0.89 & 0.12 & 0.82 & 0.10 & 0.86 & 0.11 \\
\hline $22: 5 n-3 \dagger$ & 0.80 & 0.03 & 0.80 & 0.03 & 0.75 & 0.04 & 0.70 & 0.03 & 0.80 & 0.03 & $0.68^{*}$ & 0.03 \\
\hline DHA $(22: 6 n-3) \dagger$ & 3.32 & 0.19 & $3 \cdot 20$ & 0.17 & 3.07 & 0.17 & 3.20 & 0.20 & 3.35 & 0.19 & $3.02^{*}$ & 0.18 \\
\hline SFA total & 51.00 & 0.39 & $50 \cdot 68$ & 0.47 & 51.22 & 0.43 & $49.97^{*}$ & 0.55 & 50.59 & 0.32 & $49 \cdot 71$ & 0.38 \\
\hline MUFA total & $13 \cdot 23$ & 0.27 & 13.47 & 0.24 & 13.39 & 0.44 & 13.53 & 0.25 & 12.86 & 0.31 & $14 \cdot 32$ & 0.75 \\
\hline PUFA total & 35.76 & 0.40 & 35.85 & 0.47 & 35.39 & 0.43 & 36.50 & 0.51 & 36.55 & 0.43 & $36 \cdot 27$ & 0.62 \\
\hline Total $(\mathrm{nmol} / \mathrm{ml})$ & $3762 \cdot 27$ & $179 \cdot 20$ & $3710 \cdot 31$ & 172.05 & 3843.05 & 162.56 & $3606.76^{*}$ & 177.58 & 3675.00 & 207.72 & 3647.24 & 166.68 \\
\hline
\end{tabular}

AA, arachidonic acid.

week $0(P<0.05)$

† Mean values were significantly different between the dietary treatment groups $(P<0.05)$. 
Serum lipid data have been published previously ${ }^{(7)}$. In brief, serum total cholesterol concentrations were significantly lower in both the half-dose and full-dose almond groups than in the control group. Serum LDL-C concentrations were significantly lower and serum HDL-C concentrations were significantly higher in the full-dose almond group than in the control group. Serum TAG concentrations were not affected by the dietary treatments ${ }^{(7)}$. There were no significant differences in body weight among the dietary treatment groups ${ }^{(7)}$.

\section{Fatty acid profile of dietary supplements and serum fractions}

Fatty acid composition of the dietary supplements. FA analysis of the almond and muffin supplements revealed that almonds had significantly higher amounts of OA (18:1n-9) and total FA than muffins when compared on an equal amount by weight basis (Table 1). Similar findings were recorded when the supplements were analysed on a per energy basis. As has been mentioned previously, the MUFA in almonds balanced the carbohydrate in muffins.

Changes in plasma FA concentrations after the dietary treatments reflected the FA profile of the supplements, confirming subjects' compliance with the dietary protocol. These changes were in agreement with subjects' reported compliance with the dietary protocol, which was good, ranging from $97 \cdot 8$ (SEM 0.7) to 99.5 (SEM 0.6) \% for all the three dietary treatments.

Phospholipid fraction. There was a significant increase in the concentrations of serum $\mathrm{OA}$ in the full-dose and halfdose almond groups (weeks $0-4)(P=0.001$ and $P=0.024$, respectively), while there was no significant difference in the concentrations from baseline in the control group (Table 2).

The proportions of SFA in the phospholipid fraction were positively associated with the 10-year CHD risk ( $R \quad 0 \cdot 270$, $n 80, P=0.015)$, while those of PUFA in the fraction were inversely associated with it $(R-0 \cdot 294, n 80, P=0 \cdot 008)$.

TAG fraction. There was a significant increase in the proportions of OA and MUFA in the serum TAG fraction in the half-dose $(P=0.003$ and $P=0.004$, respectively) and full-dose $(P<0.001$ and $P<0.001$, respectively) almond groups, while there was no change in the control group (Table 3; Fig. 1). The proportions of OA and MUFA in the almond groups increased significantly in a dose-dependent manner when compared with those in the control group $(P<0 \cdot 05)$.

There was a significant decrease in the proportion of palmitic acid (16:0) in the half-dose and full-dose almond groups when compared with that in the control group $(P<0 \cdot 05)$. The proportion of palmitic acid was positively associated with serum TAG concentrations $(R \quad 0.475, n$ 80, $P<0.001)$

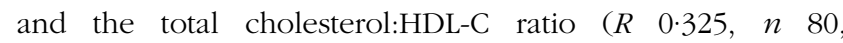

Table 3. Effect of dietary treatments on the proportions of fatty acids in the serum TAG fraction

(Mean values with their standard errors)

\begin{tabular}{|c|c|c|c|c|c|c|c|c|c|c|c|c|}
\hline \multirow[b]{4}{*}{ Fatty acids (\%) } & \multicolumn{12}{|c|}{ Dietary treatments } \\
\hline & \multicolumn{4}{|c|}{ Control (n 27) } & \multicolumn{4}{|c|}{ Half-dose almonds ( $n$ 27) } & \multicolumn{4}{|c|}{ Full-dose almonds ( $n$ 27) } \\
\hline & \multicolumn{2}{|c|}{ Week 0} & \multicolumn{2}{|c|}{ Week 4} & \multicolumn{2}{|c|}{ Week 0} & \multicolumn{2}{|c|}{ Week 4} & \multicolumn{2}{|c|}{ Week 0} & \multicolumn{2}{|c|}{ Week 4} \\
\hline & Mean & SEM & Mean & SEM & Mean & SEM & Mean & SEM & Mean & SEM & Mean & SEM \\
\hline $14: 0$ & $2 \cdot 01$ & 0.14 & $2 \cdot 01$ & 0.18 & $2 \cdot 12$ & 0.21 & $1.74^{*}$ & 0.12 & 1.96 & 0.16 & 1.85 & 0.24 \\
\hline $14: 1 n-5$ & 0.23 & 0.03 & 0.22 & 0.04 & 0.29 & 0.05 & $0.18^{*}$ & 0.03 & 0.26 & 0.06 & 0.22 & 0.05 \\
\hline $16: 0 †$ & $27 \cdot 12$ & 0.70 & $26 \cdot 41$ & 0.71 & 27.95 & 0.70 & $24.39^{*}$ & 0.66 & 26.92 & 0.80 & $24.56^{*}$ & 0.62 \\
\hline $16: 1 n-7$ & 4.01 & 0.23 & 3.94 & 0.25 & 3.93 & 0.25 & $3.41^{*}$ & 0.18 & 3.83 & 0.23 & $3 \cdot 32^{*}$ & 0.20 \\
\hline $18: 0$ & 3.73 & 0.20 & 3.60 & 0.17 & 4.02 & 0.60 & 3.46 & 0.14 & 3.96 & 0.21 & $3.44^{*}$ & 0.13 \\
\hline $18: 1 n-9 \dagger$ & 38.00 & 0.76 & 38.32 & 0.61 & 37.04 & 0.89 & $39.94^{*}$ & 0.75 & 37.37 & 0.91 & $41 \cdot 18^{*}$ & 0.86 \\
\hline $18: 1 n-7$ & $3 \cdot 17$ & 0.82 & 3.38 & 0.97 & $3 \cdot 26$ & 0.96 & 3.94 & $1 \cdot 11$ & $2 \cdot 36$ & 0.07 & 3.29 & 0.98 \\
\hline $18: 2 n-6$ & $16 \cdot 57$ & 0.76 & $16 \cdot 74$ & 0.81 & $16 \cdot 12$ & 0.81 & $17 \cdot 50^{*}$ & 0.70 & $17 \cdot 25$ & 0.75 & $17 \cdot 25$ & 0.62 \\
\hline $18: 3 n-6$ & 0.47 & 0.06 & 0.50 & 0.09 & 0.46 & 0.05 & 0.40 & 0.02 & 0.45 & 0.07 & 0.47 & 0.08 \\
\hline $20: 0 / 18: 3 n-3 \dagger$ & $1 \cdot 28$ & 0.08 & $1.53^{*}$ & 0.11 & 1.40 & 0.12 & 1.42 & 0.08 & 1.39 & 0.11 & $1 \cdot 19$ & 0.07 \\
\hline $20: 1 n-9$ & 0.21 & 0.02 & 0.23 & 0.02 & 0.23 & 0.01 & 0.23 & 0.02 & 0.24 & 0.02 & 0.25 & 0.02 \\
\hline $20: 3 n-3$ & 0.09 & 0.01 & 0.11 & 0.02 & 0.09 & 0.01 & $0 \cdot 16$ & 0.05 & 0.10 & 0.01 & 0.11 & 0.01 \\
\hline AA $(20: 4 n-6)$ & 1.26 & 0.06 & $1 \cdot 17^{*}$ & 0.07 & 1.26 & 0.08 & 1.17 & 0.05 & 1.25 & 0.09 & $1 \cdot 16$ & 0.08 \\
\hline $22: 0$ & 0.00 & 0.00 & 0.00 & 0.00 & 0.01 & 0.01 & 0.01 & 0.01 & 0.00 & 0.00 & 0.00 & 0.00 \\
\hline $22: 1 n-9$ & 0.01 & 0.01 & 0.01 & 0.01 & 0.01 & 0.00 & 0.03 & 0.02 & 0.04 & 0.02 & 0.01 & 0.01 \\
\hline EPA $(20: 5 n-3)$ & 0.38 & 0.07 & 0.50 & 0.21 & 0.32 & 0.05 & 0.40 & 0.08 & 0.75 & 0.36 & 0.22 & 0.04 \\
\hline $22: 4 n-6$ & $0 \cdot 10$ & 0.04 & 0.09 & 0.03 & 0.09 & 0.04 & $0 \cdot 10$ & 0.04 & 0.07 & 0.03 & 0.06 & 0.03 \\
\hline $24: 1 n-9$ & 0.25 & 0.14 & 0.26 & 0.13 & 0.25 & 0.14 & 0.36 & 0.18 & 0.19 & 0.13 & 0.47 & 0.20 \\
\hline $22: 5 n-6$ & 0.02 & 0.02 & 0.00 & 0.00 & 0.00 & 0.00 & 0.00 & 0.00 & 0.02 & 0.02 & 0.00 & 0.00 \\
\hline $22: 5 n-3$ & 0.31 & 0.04 & 0.35 & 0.03 & 0.34 & 0.03 & 0.36 & 0.03 & 0.36 & 0.05 & 0.29 & 0.03 \\
\hline DHA $(22: 6 n-3) \dagger$ & 0.78 & 0.13 & 0.63 & 0.08 & 0.83 & 0.15 & 0.82 & 0.09 & 1.21 & 0.28 & 0.67 & 0.10 \\
\hline SFA totalt & 33.51 & 0.87 & 32.79 & 0.89 & 34.79 & 1.15 & $30 \cdot 31^{*}$ & 0.78 & 33.54 & 0.96 & $30 \cdot 45^{\star}$ & 0.87 \\
\hline MUFA total $\dagger$ & $45 \cdot 87$ & 0.67 & $46 \cdot 36$ & 0.74 & 45.00 & $1 \cdot 11$ & $48.09^{*}$ & 0.81 & 44.29 & 0.91 & $48 \cdot 74^{\star}$ & 0.83 \\
\hline PUFA total & $20 \cdot 62$ & 0.87 & $20 \cdot 85$ & 0.90 & $20 \cdot 20$ & 0.92 & $21 \cdot 60^{\star}$ & 0.82 & $22 \cdot 16$ & 1.03 & $20 \cdot 82$ & 0.71 \\
\hline Total (nmol/ml) & $1529 \cdot 20$ & $147 \cdot 17$ & 1576.81 & 121.93 & $1653 \cdot 21$ & $155 \cdot 87$ & $1417 \cdot 45^{\star}$ & 98.88 & $1370 \cdot 61$ & 113.97 & $1418 \cdot 74^{\star}$ & $97 \cdot 17$ \\
\hline
\end{tabular}

$A A$, arachidonic acid.

${ }^{*}$ Mean value was significantly different from that at week $0(P<0.05)$.

† Mean values were significantly different between the dietary treatment groups $(P<0.05)$. 


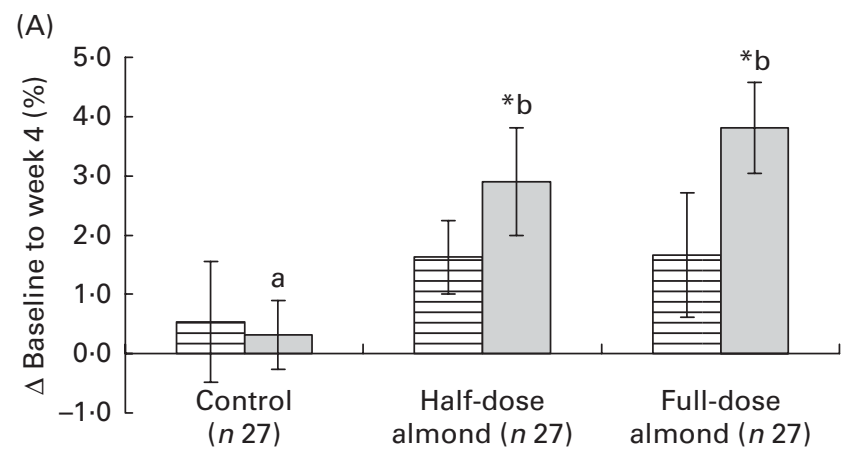

Treatment group

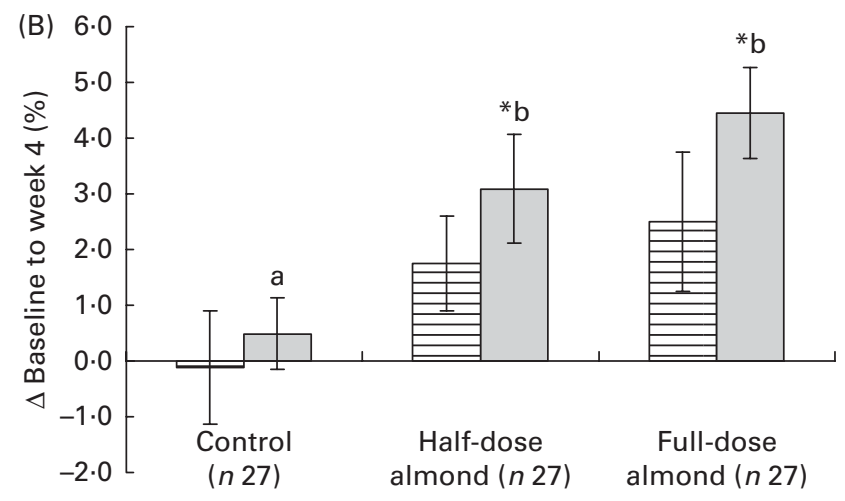

Treatment group

Fig. 1. Effect of almond dose on the change in oleic acid (18:1n-9) (A) and MUFA (B) proportions in the serum NEFA (曰) and TAG ( $\square$ ) fractions of hyperlipidaemic subjects. Values are means, with standard errors represented by vertical bars. * Mean value was significantly different from that in the NEFA fraction $(P<0.05)$. ${ }^{\mathrm{a}, \mathrm{b}}$ Mean values with unlike letters were significantly different $(P<0.05)$.

$P=0.003)$ and inversely associated with HDL-C concentrations (R 0.444, $n$ 80, $P<0 \cdot 001$ ).

The 10-year CHD risk was inversely associated with the proportions of OA $(R-0.283, n 80, P=0.011)$ and MUFA $(R-0 \cdot 269, n 80, P=0 \cdot 016)$ in the TAG fraction; this association was no longer significant when all the MUFA, except OA, were assessed (data not shown). The proportions of SFA were negatively associated with HDL-C concentrations $(R-0.428, n 80, P \leq 0.001)$ and positively associated with the 10-year CHD risk ( $R$ 0.300, $n 80, P=0 \cdot 007$ ).

No significant associations were observed between PUFA proportions and 10-year CHD risk.

Cholesterol ester fraction. There were no significant differences in the proportions of serum OA or MUFA from baseline within or between the dietary treatment groups or any significant associations between FA concentrations and blood lipid profiles or CHD risk (data not shown).

NEFA fraction. The proportions of individual FA in the serum NEFA fraction are given in Table 4. There was no change in the proportion of OA $(18: 1 n-9)$ in the control group, but an increase was observed in the almond groups (Fig. 1). However, this increase was only significant in the half-dose almond group $(P=0 \cdot 01)$, and the lack of a significant increase in the full-dose almond group is possibly due to high variability. Similarly, there was an increase in the proportions of serum MUFA in the half-dose and full-dose almond groups, but it was significant only in the half-dose almond group ( $P=0.04$ and $P=0.06$, respectively; Fig. 2).

The proportions of MUFA in the NEFA fraction were positively associated with HDL-C concentrations ( $R$ 0.329, $n$ 80, $P=0.003)$ and inversely associated with the 10-year CHD risk $(R-0.290, n 80, P=0.009)$; however, this association was significant when all the MUFA, except OA, were assessed together (data not shown). In contrast, the proportions of SFA and palmitic acid (16:0) were inversely associated with HDLC concentrations $(R-0.319, n 80, P=0.004 ; R-0.297, n 80$, $P=0.007$, respectively), possibly related to the reduction in the proportions of palmitic acid and total SFA and increase in those of MUFA after almond supplementation. The proportions of SFA and palmitic acid were also positively associated with the 10-year CHD risk ( $R$ 0.273, $n$ 80, $P=0 \cdot 014 ; R 0.331, n 80, P=0 \cdot 003$, respectively).

No significant associations were observed between the proportions of OA or PUFA in the NEFA fraction and the risk of CHD.

\section{Overall almond intake and CHD risk}

Almond intake was found to be associated with a decrease in the percentage change of the estimated Framingham 10-year CHD risk score during the study $(R-0 \cdot 247, n 81, P=0 \cdot 026)$, where for every $30 \mathrm{~g}$ increase in almond intake, a $3.5 \%$ decrease in the 10-year CHD risk was observed (Fig. 2).

\section{Discussion}

The results of the present study indicate that an isoenergetic incorporation of almonds (approximately 10 and 20\% of energy from half-dose and full-dose almonds, respectively) into a National Cholesterol Education Program Step 2 diet improves the FA profile of hyperlipidaemic adults by increasing the OA and MUFA content of serum TAG and NEFA fractions, which are inversely associated with CHD lipid risk factors and overall 10-year CHD risk.

Much of the interest in the role of MUFA in the prevention of CHD arises from the observed beneficial effects of a Mediterranean dietary pattern ${ }^{(21)}$, which is high in olive oil, providing $14-40 \%$ of energy ${ }^{(22-25)}$, and consequently high in MUFA (16-29\% of energy ${ }^{(23,26-29)}$ ) and OA. The European Prospective Investigation into Cancer and Nutrition (EPIC)Spain cohort study not only showed an association between decreased morbidity and MUFA and olive oil intake, but also showed a gradual decrease in the risk of CVD mortality with an increase in olive oil intake, where an increase of $10 \mathrm{~g} / 8368 \mathrm{~kJ}$ per d $(10 \mathrm{~g} / 2000 \mathrm{kcal}$ per d) was found to be associated with a $13 \%$ decreased risk $^{(30)}$. Similar to olive oil, almonds contain significantly high amounts of MUFA in the form of OA. The beneficial effects of almonds, particularly the MUFA component, on CHD risk observed in the present study are consistent with previous findings, including those of the Prevención con Dieta Mediterránea (PREDIMED) study $^{(31)}$. The results of a PREDIMED-based cross-over trial 
Table 4. Effect of dietary treatments on the proportions of fatty acids in the serum NEFA fraction

(Mean values with their standard errors)

\begin{tabular}{|c|c|c|c|c|c|c|c|c|c|c|c|c|}
\hline \multirow[b]{4}{*}{ Fatty acids (\%) } & \multicolumn{12}{|c|}{ Dietary treatments } \\
\hline & \multicolumn{4}{|c|}{ Control (n 27) } & \multicolumn{4}{|c|}{ Half-dose almonds ( $n$ 27) } & \multicolumn{4}{|c|}{ Full-dose almonds ( $n$ 27) } \\
\hline & \multicolumn{2}{|c|}{ Week 0} & \multicolumn{2}{|c|}{ Week 4} & \multicolumn{2}{|c|}{ Week 0} & \multicolumn{2}{|c|}{ Week 4} & \multicolumn{2}{|c|}{ Week 0} & \multicolumn{2}{|c|}{ Week 4} \\
\hline & Mean & SEM & Mean & SEM & Mean & SEM & Mean & SEM & Mean & SEM & Mean & SEM \\
\hline $14: 0$ & 1.70 & 0.10 & 1.58 & 0.13 & 1.73 & 0.11 & 1.52 & 0.12 & 1.64 & 0.14 & 1.71 & 0.16 \\
\hline $14: 1 n-5$ & 0.42 & 0.09 & 0.43 & 0.09 & 0.39 & 0.09 & 0.39 & 0.09 & 0.54 & 0.13 & 0.41 & 0.14 \\
\hline $16: 0$ & 27.00 & 0.66 & 26.58 & 0.88 & 27.58 & 0.53 & $25 \cdot 73^{\star}$ & 0.54 & $27 \cdot 12$ & 0.57 & 25.90 & 0.61 \\
\hline $16: 1 n-7$ & 3.06 & 0.21 & 2.90 & 0.21 & 3.40 & 0.34 & 3.97 & 0.88 & 3.12 & 0.26 & $3.05^{\star}$ & 0.22 \\
\hline $18: 0$ & $12 \cdot 18$ & 0.82 & $12 \cdot 11$ & 0.45 & 11.74 & 0.45 & 11.84 & 0.66 & 13.04 & 0.72 & 11.55 & 0.51 \\
\hline $18: 1 n-9$ & 33.61 & $1 \cdot 10$ & 34.14 & 0.78 & 33.36 & 0.63 & $34.98^{*}$ & 0.74 & 33.12 & 1.19 & 34.78 & 0.85 \\
\hline $18: 1 n-7$ & 2.02 & 0.10 & 2.09 & 0.08 & 2.03 & 0.08 & 2.07 & 0.08 & 2.07 & 0.10 & 2.05 & 0.09 \\
\hline $18: 2 n-6$ & 13.08 & 0.49 & 13.51 & 0.49 & $13 \cdot 30$ & 0.43 & 13.46 & 0.42 & 13.38 & 0.58 & 13.40 & 0.42 \\
\hline $18: 3 n-6$ & 0.67 & 0.48 & 0.36 & 0.25 & 0.68 & 0.49 & 0.56 & 0.48 & 0.19 & 0.16 & 1.01 & 0.61 \\
\hline $20: 0 / 18: 3 n-3$ & $1 \cdot 16$ & 0.07 & 1.27 & 0.07 & $1 \cdot 19$ & 0.07 & 1.22 & 0.07 & 1.21 & 0.08 & 1.11 & 0.06 \\
\hline $20: 1 n-9$ & 0.16 & 0.03 & 0.15 & 0.03 & 0.15 & 0.03 & 0.16 & 0.03 & 0.14 & 0.05 & 0.14 & 0.03 \\
\hline $20: 3 n-3$ & 0.04 & 0.02 & 0.26 & 0.22 & 0.02 & 0.01 & 0.21 & 0.18 & 0.01 & 0.01 & 0.02 & 0.01 \\
\hline AA $(20: 4 n-6)$ & 1.22 & 0.17 & 1.20 & 0.22 & 1.05 & 0.06 & 1.35 & 0.43 & 1.43 & 0.38 & $1 \cdot 26^{*}$ & 0.38 \\
\hline $22: 0$ & 0.00 & 0.00 & 0.00 & 0.00 & 0.00 & 0.00 & 0.00 & 0.00 & 0.00 & 0.00 & 0.00 & 0.00 \\
\hline $22: 1 n-9$ & 0.26 & 0.20 & 0.04 & 0.02 & 0.06 & 0.03 & 0.08 & 0.04 & 0.07 & 0.05 & 0.12 & 0.07 \\
\hline $\operatorname{EPA}(20: 5 n-3)$ & 0.49 & 0.29 & 0.54 & 0.34 & 0.88 & 0.47 & 0.37 & 0.29 & 1.09 & 1.01 & 0.79 & 0.43 \\
\hline $22: 4 n-6$ & 0.18 & 0.09 & 0.42 & 0.16 & 0.36 & 0.13 & 0.39 & 0.14 & 0.40 & 0.21 & 0.19 & 0.09 \\
\hline $24: 1 n-9$ & $2 \cdot 14$ & 0.95 & 1.80 & 0.68 & 1.45 & 0.64 & 0.95 & 0.54 & 0.87 & 0.50 & 1.87 & 0.64 \\
\hline $22: 5 n-6$ & 0.00 & 0.00 & 0.00 & 0.00 & 0.00 & 0.00 & 0.00 & 0.00 & 0.00 & 0.00 & 0.00 & 0.00 \\
\hline $22: 5 n-3$ & 0.10 & 0.07 & 0.11 & 0.08 & 0.11 & 0.08 & 0.04 & 0.01 & 0.03 & 0.01 & $0 \cdot 10$ & 0.09 \\
\hline DHA (22:6n-3) & 0.52 & 0.06 & 0.51 & 0.05 & 0.51 & 0.06 & 0.71 & 0.26 & 0.55 & 0.07 & 0.55 & 0.11 \\
\hline SFA & 41.46 & 1.20 & $40 \cdot 90$ & 0.97 & 41.66 & 0.83 & $39.70^{*}$ & 0.95 & 42.40 & 1.14 & $39.72^{*}$ & 1.00 \\
\hline MUFA & 41.66 & 1.11 & 41.55 & 0.81 & $40 \cdot 85$ & 0.94 & $42 \cdot 60^{\star}$ & 1.14 & 39.92 & 1.31 & $42 \cdot 42$ & 0.95 \\
\hline PUFA & $16 \cdot 88$ & 0.93 & 17.55 & 0.76 & 17.49 & 0.90 & $17 \cdot 70$ & 0.97 & 17.68 & 0.86 & $17 \cdot 86$ & 0.98 \\
\hline Total $(\mathrm{nmol} / \mathrm{ml})$ & $425 \cdot 30$ & 35.78 & 389.08 & 21.08 & 403.96 & 25.25 & 432.03 & 28.00 & 374.47 & 33.86 & 417.01 & $39 \cdot 13$ \\
\hline
\end{tabular}

AA, arachidonic acid

${ }^{\star}$ Mean value was significantly different from that at week $0(P<0.05)$.

indicated that almonds are as effective as virgin olive oil at improving risk factors for $\mathrm{CVD}^{(31)}$. In a 3-month substudy of PREDIMED, total cholesterol and TAG concentrations were found to decrease in only the Mediterranean diet with nuts (i.e. almonds, walnuts and hazelnuts) group but not in the virgin olive oil group when compared with the control group $^{(32)}$. Additional trials within PREDIMED have supported the beneficial effects of nut consumption on CHD risk. A 1-year randomised clinical trial showed that a Mediterranean dietary pattern supplemented with nuts had an antiinflammatory effect with significant reductions in the plasma concentrations of TNF receptor, IL-6 and intercellular adhesion molecule 1, which are circulating inflammatory biomarkers associated with CHD risk ${ }^{(33)}$. This dietary pattern was further shown to be protective against the primary endpoints of CHD. The resulting multivariate analysis value obtained in a long-term (median 4.8 years) PREDIMED randomised multicentre trial of a Mediterranean diet with nuts $v$. a control diet was $0.72(95 \%$ CI $0.54,0.96 ; P=0.03)$ with respect to the primary endpoint, which was a composite of myocardial infarction, stroke and death from cardiovascular causes ${ }^{(6)}$.

Although the mechanism by which almonds modify CHD risk is unclear, it has been proposed that almonds may exert an effect exogenously and endogenously. It has been proposed that dietary incorporation of almonds exogenously reduces serum cholesterol concentrations by replacing saturated fats with monounsaturated fats in the diet. In a randomised, controlled, parallel study, the SFA concentrations of thirty-eight hypercholesterolaemic adults who consumed $100 \mathrm{~g}$ of raw almonds daily over a 4-week period were found to be lower ${ }^{(34)}$. Furthermore, increasing MUFA intake has been reported to be associated with an increase in HDL-C concentrations, as demonstrated by a randomised, controlled trial of twenty-four hypercholesterolaemic adults ${ }^{(35)}$. The improvement in blood lipid profiles has generally been associated with a reduced risk of CHD. However, this may not apply to the present study as we focused on a MUFAcarbohydrate substitution. It has also been proposed that

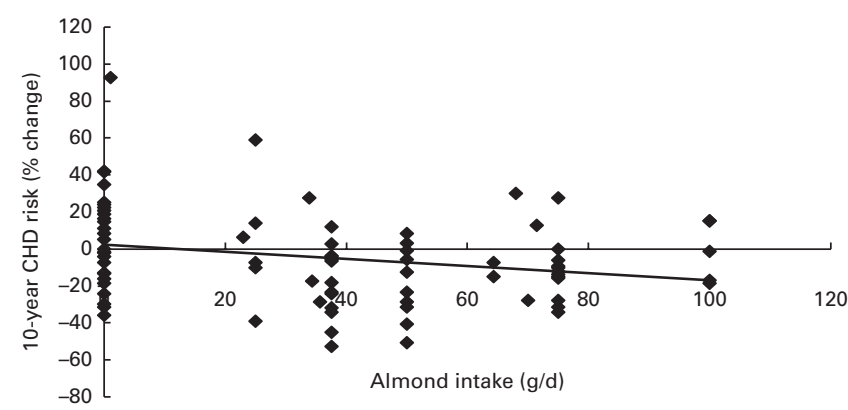

Fig. 2. Regression analysis on the association between almond consumption and percentage change of the estimated 10-year $\mathrm{CHD}$ risk score using the Framingham equation $(R-0.247, n 81, P=0.026)$. 
almonds may act endogenously to exert a cardioprotective effect. Dietary FA are rapidly incorporated into lipoprotein lipids. Enrichment of lipoprotein particles with MUFA at the expense of PUFA may enhance their resistance to oxidative stress as there are few double bonds to react with, thus potentiating the anti-atherogenic effect ${ }^{(36-38)}$. Plasma phospholipid, cholesterol ester, TAG and NEFA compositions are responsive to total dietary fat content, though NEFA and TAG are the major forms of lipids found in circulation ${ }^{(39)}$.

There are several limitations to the present study. $\alpha$-Linolenic acid (18:3n-3) did not get separated from arachidic acid $(20: 0)$ during chromatographic analysis. Almonds are low in $\alpha$-linolenic $\operatorname{acid}^{(10)}$ and would not be expected to significantly alter serum concentrations; however, neither this nor any associations between changes in serum $\alpha$-linolenic acid concentrations and CHD risk could be verified from the findings of the present study. Moreover, in the present study, almond consumption was found to increase faecal MUFA excretion (RP Bazinet and CWC Kendal, unpublished results), indicating an attenuated effect due to the inaccessibility of some of the nutrients and energy from almonds for absorption ${ }^{(40)}$. This is further supported by findings from previous studies, which suggest that nuts contain less metabolisable energy than expected based on Atwater general factors and that the lipid from nuts is more poorly absorbed than that from other food sources ${ }^{(41)}$

Despite these limitations, the findings of the present study suggest that the FA profile of almonds has the potential to contribute to the total reduction of CHD risk. The cholesterollowering effect of almond consumption is explained, in part, by the FA profile of almonds, especially MUFA; however, there may be other bioactive components in almonds that further reduce CHD risk. In addition to unsaturated FA, almonds are a good source of vitamin $\mathrm{E}$, fibre and phytochemicals (phenols, flavonoids, proanthocyanidins and phytosterols), arginine, $\mathrm{Cu}$ and $\mathrm{Mg}$, which may beneficially influence CHD risk ${ }^{(42-44)}$. Many of these nutrients may act synergistically to produce the observed favourable outcomes, although further studies are required to prove this postulation $^{(42)}$. Further analysis of LDL particle size may provide a better understanding of potential mechanisms by which almonds and other foods rich in MUFA influence TAG concentrations.

In conclusion, the results of the present study indicate that almond consumption favourably alters the serum FA profile by increasing the proportions of OA and total MUFA and decreasing those of SFA. These changes in the FA profile are correlated with improvements in blood lipoproteins and with a decreased 10-year CHD risk.

\section{Supplementary material}

To view supplementary material for this article, please visit http://dx.doi.org/10.1017/S0007114514001640

\section{Acknowledgements}

The authors thank Tzu Han Chuck Chen and Byung Jun Song for their exceptional technical assistance.
Aspects of the present study have been presented at Experimental Biology, San Diego, CA, 21-25 April 2012.

The present study was supported by the Canada Research Chair Endowment of the Federal Government of Canada and the Almond Board of California, Modesto, CA, USA. None of the funding organisations or sponsors played any role in the design and conduct of the study; in the collection, management, analysis and interpretation of the data; or in the preparation, review or approval of the manuscript.

C. W. C. K., R. P. B. and D. J. A. J. had full access to all the data in the study and were responsible for the integrity of the data and the accuracy of the data analysis. C. W. C. K. and D. J. A. J. obtained funding. C. W. C. K., R. P. B., K. G. L. and D. J. A. J. were responsible for study concept and design. S. N., C. W. C. K., R. P. B., B. B., A.-M. G. and D. J. A. J. were responsible for the acquisition and analysis of data. S. N., C. W. C. K., A.-M. G., R. P. B., K. G. L., L. S. A. A., J. L. S. and D. J. A. J. were responsible for the interpretation of data. S. N., C. W. C. K. and R. P. B. drafted the manuscript. S. N., C. W. C. K., A.-M. G., R. P. B., B. B., K. G. L., L. S. A. A. and J. L. S. provided administrative, technical and material support. C. W. C. K., R. P. B., B. B. and D. J. A. J. supervised the study. All authors critically revised the manuscript for important intellectual content and approved the manuscript submitted for publication.

D. J. A. J. has served on the Scientific Advisory Board of Unilever, Sanitarium Company, California Strawberry Commission, Loblaw Supermarket, Herbal Life International, Nutritional Fundamental for Health, Pacific Health Laboratories, Metagenics, Bayer Consumer Care, Orafti, Dean Foods, Kellogg's, Quaker Oats, Procter \& Gamble, Coca-Cola, NuVal Griffin Hospital, Abbott, Pulse Canada, Saskatchewan Pulse Growers and Canola Council of Canada; is receiving honoraria for scientific advice from the Almond Board of California, International Tree Nut Council Nutrition Research and Education Foundation, Barilla, Unilever Canada, Solae, Oldways, Kellogg's, Quaker Oats, Procter \& Gamble, Coca-Cola, NuVal Griffin Hospital, Abbott, Canola Council of Canada, Dean Foods, California Strawberry Commission, Hain Celestial and Alpro Foundation; is on the speakers panel of the Almond Board of California; is receiving research grants from Loblaw Brands Limited, Unilever, Barilla, Almond Board of California, Solae, Hain Celestial, Sanitarium Company, Orafti, International Tree Nut Council Nutrition Research \& Education Foundation, and Peanut Institute and receiving travel support to meetings from the Almond Board of California, Unilever, Alpro Foundation, and International Tree Nut Council, Canadian Institutes for Health Research, Canada Foundation for Innovation, Ontario Research Fund. D. J. A. J. is receiving salary support as a Canada Research Chair from the federal government of Canada. His wife is a director of Glycemic Index Laboratories, Toronto, Ontario, Canada. C. W. C. K. has received research grants, travel funding, consultant fees and honoraria from and has served on the Scientific Advisory Board of Abbott Laboratories, Advanced Food Materials Network, Agrifoods and Agriculture Canada, Almond Board of California, American Peanut Council, American Pistachio Growers, Barilla, California Strawberry Commission, Energy Control Council, Canadian Institutes 
of Health Research (CIHR), Canola Council of Canada, The Coca-Cola Company (investigator initiated, unrestricted), Danone, General Mills, Hain Celestial, International Tree Nut Council, Kellogg's, Kraft, Loblaw Brands Limited, Nutrition Foundation of Italy, Oldways, Orafti, Paramount Farms, Peanut Institute, Pepsi-Co, Pulse Canada, Saskatchewan Pulse Growers, Solae, Sun-Maid, Tate \& Lyle, and Unilever. J. L. S. has received research support from the CIHR, Energy Control Council, The Coca-Cola Company (investigator initiated, unrestricted grant), Pulse Canada, and International Tree Nut Council Nutrition Research \& Education Foundation. He has received travel funding, speaker fees and/or honoraria from the American Heart Association, American College of Physicians, American Society for Nutrition (ASN), National Institute of Diabetes and Digestive and Kidney Diseases of the National Institutes of Health, Canadian Diabetes Association (CDA), Canadian Nutrition Society, Calorie Control Council, Diabetes and Nutrition Study Group of the European Association for the Study of Diabetes (EASD), International Life Sciences Institute (ILSI) North America, ILSI Brazil, Abbott Laboratories, Pulse Canada, University of South Carolina, University of Alabama at Birmingham, Oldways Preservation Trust, Nutrition Foundation of Italy (NFI), Corn Refiners Association, World Sugar Research Association, Dr Pepper Snapple Group and The Coca-Cola Company. He has consulting arrangements with Winston \& Strawn LLP and Tate and Lyle. He is on the Clinical Practice Guidelines Expert Committee for Nutrition Therapy of both the CDA and EASD, as well as on the ASN writing panel for a scientific statement on the metabolic and nutritional effects of fructose, sucrose and high-fructose corn syrup. He is an unpaid scientific advisor for the ILSI North America, Food, Nutrition, and Safety Program. His wife is an employee of Unilever Canada. K. G. L. is an employee of the Almond Board of California. No other potential conflicts of interest relevant to the study exist.

\section{References}

1. Frazer GE, Sabate J, Beeson WL, et al. (1992) A possible protective effect of nut consumption on risk of coronary heart disease. The Adventist Health Study. Arch Intern Med 152, $1416-1424$

2. Hu FB, Stampfer MJ, Manson JE, et al. (1998) Frequent nut consumption and risk of coronary heart disease in women: prospective cohort study. BMJ 317, 1341-1345.

3. Ellsworth JL, Kushi LH \& Folsom AR (2001) Frequent nut intake and risk of death from coronary heart disease and all causes in postmenopausal women: the Iowa Women's Health Study. Nutr Metab Cardiovasc Dis 11, 372-377.

4. Albert CM, Gaziano JM, Willett WC, et al. (2002) Nut consumption and decreased risk of sudden cardiac death in the Physicians' Health Study. Arch Intern Med 162, 1382-1387.

5. Sabate J, Oda K \& Ros E (2010) Nut consumption and blood lipid levels: a pooled analysis of 25 intervention trials. Arch Intern Med 170, 821-827.

6. Estruch R, Ros E, Salas-Salvado J, et al. (2013) Primary prevention of cardiovascular disease with a Mediterranean diet. N Engl J Med 368, 1279-1290.
7. Jenkins DJ, Kendall CW, Marchie A, et al. (2002) Dose response of almonds on coronary heart disease risk factors: blood lipids, oxidized low-density lipoproteins, lipoprotein(a), homocysteine, and pulmonary nitric oxide: a randomized, controlled, crossover trial. Circulation 106, $1327-1332$.

8. Spiller GA, Jenkins DAJ, Bosello O, et al. (1998) Nuts and plasma lipids: an almond-based diet lowers LDL-C while preserving HDL-C. J Am Coll Nutr 17, 285-290.

9. Kris-Etherton PM, Hu FB, Ros E, et al. (2008) The role of tree nuts and peanuts in the prevention of coronary heart disease: multiple potential mechanisms. J Nutr $\mathbf{1 3 8}$, 1746S-1751S.

10. Robbins KS, Shin EC, Shewfelt RL, et al. (2011) Update on the healthful lipid constituents of commercially important tree nuts. J Agric Food Chem 59, 12083-12092.

11. Kris-Etherton PM (1999) Monounsaturated fatty acids and risk of cardiovascular disease. Circulation 100, 1253-1258.

12. Sathe SK, Seeram NP, Kshirsagar HH, et al. (2008) Fatty acid composition of California grown almonds. J Food Sci $\mathbf{7 3}$, C607-C614.

13. Maguire LS, O'Sullivan SM, Galvin K, et al. (2004) Fatty acid profile, tocopherol, squalene and phytosterol content of walnuts, almonds, peanuts, hazelnuts and the macadamia nut. Int J Food Sci Nutr 55, 171-178.

14. Sanders TA (2001) Olive oil and the Mediterranean diet. Int J Vitam Nutr Res 71, 179-184.

15. Garg A, Bonnanome A, Grundy SM, et al. (1988) Comparison of a high-carbohydrate diet with a high-monounsaturated-fat diet in patients with non-insulin-dependent diabetes mellitus. $N$ Engl J Med 319, 829-834.

16. Wilson PW, Castelli WP \& Kannel WB (1987) Coronary risk prediction in adults (the Framingham Heart Study). Am J Cardiol 59, 91G-94G.

17. Lipid Research Clinics (1982) Population Studies Data Book. Volume II. The Prevalence Study - Nutrient Intake. Washington, DC: US Government Printing Office, US Department of Health and Human Services (NIH Publication No. 82-2014).

18. Lipid Research Clinics (1982) Manual of Laboratory Operations. Lipid and Lipoprotein Analysis (revised 1982). US Department of Health and Human Services publication no. (NIH) 75-678. Washington, DC: US Government Printing Office.

19. Jenkins DJ, Kendall CW, Popovich DG, et al. (2011) Effect of a very-high-fiber vegetable, fruit, and nut diet on serum lipids and colonic function. Metabolism 50, 494-503.

20. Folch J, Lees M \& Sloane Stanley GH (1957) A simple method for the isolation and purification of total lipides from animal tissues. J Biol Chem 226, 497-509.

21. Bhupathiraju SN \& Tucker KL (2011) Coronary heart disease prevention: nutrients, foods, and dietary patterns. Clin Chim Acta 412, 1493-1514.

22. Zizza C (1997) The nutrient content of the Italian food supply 1961-1992. Eur J Clin Nutr 51, 259-265.

23. Trichopoulou A, Katsouyanni K \& Gnardellis C (1993) The traditional Greek diet. Eur J Clin Nutr 47, Suppl. 1, S76-S81.

24. Serra-Majem L, Ribas L, Lloveras G, et al. (1993) Changing patterns of fat consumption in Spain. Eur J Clin Nutr $\mathbf{4 7}$, Suppl. 1, S13-S20.

25. Kris-Etherton P, Eckel RH, Howard BV, et al. (2001) AHA Science Advisory: Lyon Diet Heart Study. Benefits of a Mediterranean-style, National Cholesterol Education Program/ American Heart Association Step I Dietary Pattern on Cardiovascular Disease. Circulation 103, 1823-1825.

26. Keys A (1970) Coronary heart disease in seven countries. Circulation 41, Suppl. 1, 1-211. 
27. Tricopoulous A, Toupadaki N, Tzonou A, et al. (1993) The macronutrient composition of the Greek diet: estimates derived from six case-control studies. Eur J Clin Nutr $\mathbf{4 7}$, 549-558

28. Martin-Moreno JM, Boyle P, Gorgojo L, et al. (1993) Development and validation of a food frequency questionnaire in Spain. Int J Epidemiol 22, 512-519.

29. Moreiras-Varela O (1989) The Mediterranean diet in Spain. Eur J Clin Nutr 43, Suppl. 2, 83-87.

30. Buckland G, Mayen AL, Agudo A, et al. (2012) Olive oil intake and mortality within the Spanish population (EPICSpain). Am J Clin Nutr 96, 142-149.

31. Damasceno NRT, Perez-Heras A, Serra M, et al. (2011) Crossover study of diets enriched with virgin olive oil, walnuts or almonds. Effects on lipids and other cardiovascular risk markers. Nutr Metab Cardiovasc Dis 21, S14-S20.

32. Estruch R, Martinez-Gonzalez MA, Corella D, et al. (2006) Effects of a Mediterranean-style diet on cardiovascular risk factors: a randomized trial. Ann Intern Med 145, 1-11.

33. Urpi-Sarda M, Casas R, Chiva-Blanch G, et al. (2012) The Mediterranean diet pattern and its main components are associated with lower plasma concentrations of tumor necrosis factor receptor 60 in patients at high risk for cardiovascular disease. J Nutr 142, 1019-1025.

34. Spiller GA, Miller A, Olivera K, et al. (2003) Effects of plantbased diets high in raw or roasted almonds, or roasted almond butter on serum lipoproteins in humans. $J$ Am Coll Nutr 22, 195-200.

35. Jenkins DJA, Chiavaroli L, Wong JMW, et al. (2010) Adding monounsaturated fatty acids to a dietary portfolio of cholesterol-lowering foods in hypercholesterolemia. CMAJ 182, 1961-1967.
36. Tsimikas S, Philis-Tsimikas A, Aslexopoulos S, et al. (1999) LDL isolated from Greek subjects on a typical diet or from American subjects on an oleate-supplemented diet induces less monocyte chemotaxis and adhesion when exposed to oxidative stress. Arterioscler Thromb Vasc Biol 19, 122-130.

37. Berry EM, Eisenberg D, Haratz D, et al. (1991) Effects of diets rich in monounsaturated fatty acids on plasma lipoproteins the Jerusalem Nutrition Study: high MUFAs vs high PUFAs. Am J Clin Nutr 53, 899-907.

38. Ros E \& Mataix J (2006) Fatty acid composition of nuts implications for cardiovascular health. Br J Nutr 96, Suppl. 2, S29-S35.

39. Raatz SK, Bibus D, Thomas W, et al. (2001) Total fat intake modifies plasma fatty acid composition in humans. $J$ Nutr 131, 231-234.

40. Ellis PR, Kendall CW, Ren Y, et al. (2004) Role of cell walls in the bioaccessibility of lipids in almond seeds. Am J Clin Nutr 80, 604-613.

41. Baer DJ, Gebauer SK \& Novotny JA (2012) Measured energy value of pistachios in the human diet. Br J Nutr 107, $120-125$.

42. Kris-Etherton PM, Zhao G, Binkoski AE, et al. (2001) The effects of nuts on coronary heart disease risk. Nutr Rev 59, 103-111.

43. Bolling BW, Chen O, McKay D, et al. (2011) Tree nut phytochemicals: composition, antioxidant capacity, bioactivity, impact factors. A systematic review of almonds, Brazils, cashews, hazelnuts, macadamias, pecans, pine nuts, pistachios and walnuts. Nutr Res Rev 24, 244-275.

44. Bolling BW, Dolnikowski G, Blumberg JB, et al. (2010) Polyphenol content and antioxidant activity of California almonds depend on cultivar and harvest year. Food Chem 122, 819-825. 